MATEC Web of Conferences 40, 07008 (2016)

DOI: $10.1051 /$ matecconf/20164007008

(C) Owned by the authors, published by EDP Sciences, 2016

\title{
Introduction to the RFID Technology in the Application of the Smart Supermarket
}

\author{
Binbin $\mathrm{FU}^{1}$, Bingjian $\mathrm{LI}^{1}$, Ruiping YUAN ${ }^{1}$ \\ ${ }^{1}$ Information of school, Beijing WUZI university, Beijing, China
}

\begin{abstract}
RFID technology is no stranger to more or less have contacted various of industries in nowadays. Premier wen Jiabao put forward the "experience China" in 2009, after the application of IOT (Internet of things) is rocketed development and RFID technology is absolutely necessary as the core of IOT. On the experiment background of campus supermarket, this paper briefly introduces the application of RFID technology in the intelligent supermarket that mainly included four parts. Through analysis of system, it detailed interpretation that IOT bring changes to campus supermarket.
\end{abstract}

\section{Summary}

The widening of school scale, the increasing number of students, this attracts the attention to the more retail companies. However, after 90 students of a variety of jumping thinking, a different ways of purchase, purchasing type and time variable has brought about many problems to the campus supermarket. To seize 90 the desire to buy, to improve the efficiency of traditional operation has become difficult problem of school management. The emergence of IOT renewed hope the supermarket management of the school.

\section{INTRODUCTION OF IOT AND RFID TECHNOLOGY}

\subsection{Introduction of IOT}

IOT (Internet of Things), the word was first proposed by MIT Auto - ID Ashton a professor when he researched RFID in 1999. IOT, the concept, is established formally by world summit on the information society held in Tunisia in $2005^{[1]}$. Currently the world's more recognized meaning is that with the global unified identification coding technology to every object a unique code, through RIFD (radio frequency identification), two-dimensional code, global positioning system (GPS), bar code, laser scanner, infrared sensors all the modern information technology put every object connected to the Internet, which can be used to recognition, track, location and management ${ }^{[2]}$.

\subsection{Introduction of the RFID technology}

As a kind of communication technology, RFID technology, identify specific objectives and read and write related data via radio signal, without identification system building a mechanical or optical connection with the objectives. The RFID electronic tag is small in size, shape variety; Strong pollution resistance and durability; Strong penetrability; Memory storage capacity; Reusable. According to different frequencies, the RFID system consists of high frequency, intermediate frequency and low frequency systems .RFID is the use of electromagnetic induction, radio waves or microwaves to transmit information by non-contact coupling space and to achieve the purpose of identification and exchange of technical data by the transmission of information ${ }^{[3]}$.

\section{The composition of smart supermarket}

RFID technology was applied to intelligent supermarket, enabling access control system security, and real-time monitoring and dynamic management of goods quantity change on the shelves of the shopping process. Smart supermarket was a new shopping experience, and maybe change generational habits of shopping. Intelligent supermarket biggest feature is the use of RFID radio frequency identification technology, without manual for 
each item barcode scanning. Because radio signal can penetrate obstacles such as clothes, this also can prevent supermarket goods stolen ${ }^{[4]}$.Therefore, this article make supermarket shopping links intelligent transformation such as the self-take container, shelves, clearing channel, so it realize shopping flow process simplification, highspeeding, efficient and intelligent. Intelligent supermarket system is mainly composed of four subsystem.

\subsection{Smart supermarket shelves background system}

Intelligent shelves background system based on RFID technology, using RFID technology to identify, read and transmit data with background management system. Shelves system can automatic stock check goods on the selves, real-time statistics number of goods. Shelves goods can be display inventory information regularly via LED screen, such as out of stock can be scroll the display through the LED unit and voice prompt. This system will simulate the stock warehouse of supermarket that complete with stock replenishment and goods in.

Light guidance picking system based on the laser control technologies, according to send the order picking information form the background system, will order information such as picking type, size and quantity of goods, display in background shelves LED by the light projector screen. Then sorter packs out order need goods according to the LCD screen information, finished picking process.

\subsubsection{System structure}

Intelligent shelves background system based on RFID technology, receives goods shelves of electronic tags and reads the electronic tag information by UHF RFID antenna, and then processing by the reader. It contact the PC system to establish communication by WIFI signal. The system record the amount and type of goods on the shelves, real-time monitoring of changes in the number of goods.

Light guidance picking system based on the laser control technologies, acquires the order information by PC system sent to the central processor, the central processor parse order information, which reordering the packing out the order of goods, statistics of the number and variety, and then converted processed information into instruction that command the direction and content of the projector, guide sorter picking, when packing finished, the sorter press the confirm button, then intelligent shelves make information feedback to the central processor by WIFI signal.

\subsubsection{System function description}

Intelligent background system based on RFID technology can be efficiently to real-time dynamic monitoring of inventory, and safety stock alert. Light guidance picking system can be using light projection system for picking guide. Their main functions are as follows:

Inventory statistics functions: intelligent shelves can be real-time monitoring and statistics the variety and quantity of goods on the shelves, and through the WIFI return data information feedback to the central database.

Commodity management functions: can know realtime the inventory and sales information. You can look at the price, category, location, discount information of a commodity, at the same time can check the goods on the shelves and inventory from supermarket background system, This strengthen the supermarket information sharing.

Inventory alert functions: intelligent shelves set a minimum number control line of various types of goods in the inventory quantities, reaching the minimum amount of inventory control, safety stock, it will warn automatically to remind managers for replenishment.

Light guidance function: central processor converted processed information into instruction that specify orientation and content of the projector that guidelines pickers picking after the light content projection on the shelves screen.

\subsection{Smart take-self container system}

When express parcel put into take-self container, the system will inform owner to receive delivery by SMS automatically. The customer use the password in the SMS to get back packages at any time, without waiting at home for express ${ }^{[5]}$. Hence the take-self container system can be applied to office buildings, shopping malls, supermarkets, community, etc. to solve the last kilometer problem.

Intelligent take-self container system is mainly by the cabinet, cell and main control unit composed of three parts, main control unit contains internal microcomputer, reader and other major parts. Internal the microcomputer control cabinet tank and access operation.

Authentication functions: intelligent control unit according to consignee input code automatic identify consignee, after verification and will automatically open cell let people to take away orders for goods.

Stored custody functions: intelligent take-self container can solve consignee not take away parcel due to various reasons, improve flexible of the pick-up time. During the period of stay to take custody of goods without the correct verification code can't open the cell and remove goods.

\subsection{Smart supermarket shelves foreground system}


Smart supermarket foreground shelves complete the goods on the shelves real-time monitoring. Record commodity storage time, departure time, each layer of shelf products placed state.

\subsubsection{System structure}

Smart supermarket foreground shelves by antenna and RFID reader to receive and identify the goods electronic tag information, so that statistics and feedback the supermarket goods types and quantity to administrator realize the real-time shelves products dynamic monitoring. At the same time, consumers can check goods detailed information from screen.

\subsubsection{System function description}

- for consumers:

Query functions: Foreground shelves system with a touch screen devices, shoppers can view the commodity information, and guide for voice through the touch screen devices.

Self-checkout functions: It is use to self-checkout operation for smart and not shopping cart (with RFID reader or bar code reader, it read product information and checkout).

- for the supermarket background management:

Monitoring functions: It provides goods storage time, leaving time, each layer goods of shelf place state information to background administrator

Replenishment alarm functions: setting up goods quantity minimum control line on the shelves, when the number of goods shelves reached a critical state, smart shelves foreground system send a replenishment warning to administrators.

Information sharing functions: The system support real-time multiple terminals information sharing.

\subsection{Smart clearing channel system}

Smart clearing channel system mainly include RFID settlement channels and intelligent supermarket foreground and background software system. It is quick checkout service. System is using UHF RFID technology to scan personnel card information and cargo information in shopping car. First it identify personnel RFID card, enter the corresponding membership information, and then RFID channel scan all goods RFID tags in the shopping cart, statistics the number of goods in shopping car and corresponding price in the database to determine whether a discount, the final price will be accounted for.

\subsubsection{System structure}

RFID clearing channel after scanning tag in the shopping cart automatically add to the total number of statistics and price, and the information feedback to a central server. Consumers do settlement of accounts through intelligent supermarket foreground system, which deduct the corresponding amount of consumer card, complete the payment.

\subsubsection{Smart supermarket settlement system description}

Click clearing goods button on the shopping cart screen, it will enter the goods settlement interface, which shows all the items in the cart. If you don't use smart shopping cart add to goods, when you cross clearing channel, invalid commodity will be display on the screen. Customers can add the invalid goods to cart or removed according to his own need.

\section{Conclusion}

With the rapid development of IOT technology, which application in the field of intelligent opened the broad prospect, and earlier applied to the wisdom of logistics and other areas ${ }^{[6]}$.In the current social conditions, indepth process of campus information technology, construction of "digital campus" has become an important task of the management work in colleges and universities $^{[7]}$. This paper, according to the actual situation and the related requirements of school, supported by RFID technology, combined with the traditional campus supermarket construction design idea, the user can self-service shopping settlement or temporary existence in the self-take container makes the system convenient and operation flexible, efficiency, fully functional. There are a lot of extensible space in the future for realization of digital campus, smart campus to make some contribution.

\section{Acknowledgements}

This paper is supported by the Funding Project for Technology Key Project of Municipal Education Commission of Beijing (ID:TSJHG20131003703 6), Funding project for Beijing Key Laboratory of Intelligent Logistics System; Funding Project of Construction of Innovative Teams and Teacher Career Development for Universities and Colleges Under Beijing Municipality(ID: IDHT20130517). Beijing Municipal Science and Technology Project (ID: Z131100005413004), Funding project for Beijing philosophy and social science research base specially commissioned project planning (ID: 13JDJGD013).

\section{References}

1. Xia LI. Introduction to logistics information technology and the Internet of things [J] Business Modernization.2010 (15) 
2. Xiaoqing KONG,Junjun LI. Research on the Internet of things technology application and development [J] Computer CD Software and Applications. 2014(02)

3. Yunjun GUO,Xuanzheng XUAN, Shengshu SUN. The student dormitory entrance guard system design based on RFID technology [J] Scientific and Technological Information. 2014(04)

4. Liya LI,Shuhua MAO. Problem analysis of RFID applied in the intelligent supermarket [J] RFID WorldNet

5. Urban development editorial department. The solution of the last one kilometer Express [J] Urban development

6. Guanglin LEI,Jun LI. The wisdom of campus application and practice based on the Internet of things[J]Logistics technology, Research and Exploration in Laboratory.2012(09)

7. Bin WANG.The campus one-card system construction based on RFID technology [D] 2008(10) 